\title{
Impact of Trust Factors in Improvement and Development of E-commerce in Saudi Arabia
}

\author{
Hosam El-Sofany Turki Al-Malki
}

Abdul-Aziz AlZamel

Abdul-Aziz Alharbi

Arab East Colleges for Graduate Studies, Department of Computer Science, Riyadh, Kingdom of Saudi Arabia.

\begin{abstract}
E-commerce is the basic technology of knowledge economy. Developing and improving of e-commerce is an inevitable choice for Saudi Arabia economy to enter strongly into the world market, and bring about a great economic grows of the K.S.A nation. Before we can start developing or improving ecommerce and knowing the different factors that affect it, we have to understand the background, the basic principle and the evolution and development history of e-commerce. This enables us to have a deep understanding on this new technology, hence, helping us to predict the success factors and trend of e-commerce in the near future. This paper introduces some basic knowledge regarding to e-commerce, which includes, the needs of society, development of ecommerce, and basic e-commerce concepts. Gain of Saudi customer' trust in the e-commerce services is very important for the long-term growth of many businesses. The main objective of this paper is to identify and analyze the main factors that influence the extent to which Saudi consumers trust towards the B2C e-commerce. The challenge for the research is to determine the e-commerce model and identify trust factors that consistent with the traditions of Saudi Arabia and maximizes the purchaser trust when shopping through the internet. The paper will conclude with quantitative analysis of responses obtained from a survey and questionnaire of selected customers and businesses in Saudi Arabia. The main results of this analysis include a relationship of key factors that affect the trust of Saudi consumers in the e-commerce, and the indicators of strengths and weaknesses that affect these factors.
\end{abstract}

\section{Keywords}

e-commerce, m-commerce, business to business (B2B), business to consumer (B2C), business to governments (B2G), consumers to consumers $(\mathrm{C} 2 \mathrm{C})$, governments to governments (G2G), consumers trust.

\section{INTRODUCTION}

E-commerce is the core technology of knowledge economy. Developing e-commerce is an inevitable choice to enter into the world market, participate in and ultimately penetrate the global market. Before we can start developing e-commerce, we have to understand the background, the basic principle and the evolution and development history of e-commerce.

There are extensive researches for examining the trust factors of e-commerce, which affect the level of trust need by purchasers for participating in an e-commerce transaction. These include:

- The purchaser's perception of the risks [25].

- The purchaser's motivation for buying, and the reputation of the seller [26].
- Trust in service-oriented environments has been examined extensively in [12], where trust is defined as "the belief the trusting agent has examined the trusted agent's willingness and capability to deliver a mutually agreed service in a given context and in a given time slot".

- Some researchers suggested that a risk reliever should address multiple purchasing risks; however, they find that assurance seals performing multiple functions are not necessarily more effective than single-function seals in enhancing consumers' initial online trust [16].

The paper is organized as follows: in section two, we present the e-commerce concepts and definitions. In section three, we introduce a condensed survey and a literature review, about the factors that affect the e-commerce transactions. In section four, we introduce the trust factors that consistent with the traditions of Saudi Arabia and maximize the purchaser trust when shopping through the internet. In section five, we present the research methodology. The paper finally concluded in section six with discussing the quantitative analysis of responses that obtained from a survey and questionnaire of selected customers and businesses in Saudi Arabia.

\section{E-COMMERCE CONCEPTS}

It is clear that e-commerce is a very broad concept and does not have a clear-cut definition. One way of defining it, is that, it is a way of doing business transactions via the internet. Ecommerce or e-business is based on the electronic processing and transmission of data, including text, sound, and video. $E$ commerce is defined as, "the use of technology to conduct financial transactions online". E-commerce refers to various online commercial activities focusing on commodity exchanges by electronic means, internet in particular, by companies, factories, enterprises, industrial undertaking and consumers. The following are some definitions

given by transnational corporations such as: Intel, IBM and HP respectively [22]:

Intel: E-commerce $=$ electronic market + electronic trade + electronic service

IBM: E-commerce = information technology + web + business

HP : E-commerce is a brand new science; it is not at all surprising that there are various definitions about it. 


\subsection{The Origin and Development of E- commerce}

Internet has created a new world beyond the real world - a "virtual network world". E-commerce brought about by internet is one of the most significant scientific accomplishments. In business, the prosperous e-commerce technology gives rise to a revolution in the circulation system. It breaks the boundary of time and space, reduces the cost of production effectively, and has enabled the traditional business to achieve greater, faster, better and more economical results. The development of computer science and communications sciences has laid a solid foundation for ecommerce. The development of information security makes ecommerce proceed in a secure way; the laws concerning this field also provide legal guarantees for e-commerce. The origin and development of e-commerce is composite of three phases as illustrated in Figure 1, [22]:

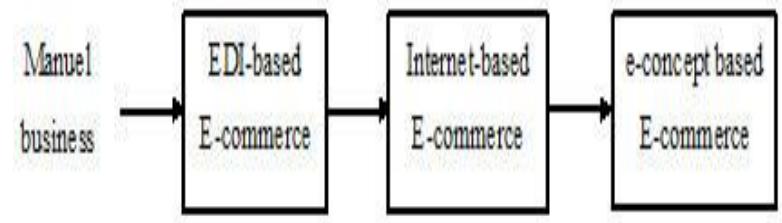

Figure 1: The Development of E-commerce

I. E-commerce based on EDI (Electronic Data Interchange): The EDI originated in the $60 \mathrm{~s}$ of the $20^{\text {th }}$ century. The large-scaled business enterprises in the developed countries carried out the EDI basically in the 80 s.

II. E-commerce based on internet: In the middle and the late $90 \mathrm{~s}$ of the $20^{\text {th }}$ century, business that has always been outside of internet came into the realm and made ecommerce a big hit in internet, which gives impetus to the rapid development of internet. The reason why ecommerce bases on internet is so attractive to enterprises is that e-commerce enjoys several evident advantages over e-commerce based on EDI: 1- low in cost, 2- wide in overlaying, 3- complete in function, 4- and flexible in use.

III. E-concept e-commerce: Since 2000, people's understanding is developed and they realized that ecommerce is in fact the combination of information technology and commerce applications.

\subsection{E-commerce Market Models}

The major different types of e-commerce are: business to business (B2B); business-to-consumer (B2C); business-togovernment (B2G); consumer-to-consumer (C2C); and mobile commerce (M-commerce) [10].

I. B2B e-commerce: is simply defined as e-commerce between companies. This is the type of e-commerce that deals with relationships between and among businesses. About $80 \%$ of e-commerce is of this type, and most experts predict that $\mathrm{B} 2 \mathrm{~B}$ e-commerce will continue to grow faster than the B2C segment [10].

The more common $\mathrm{B} 2 \mathrm{~B}$ examples and best practice models are IBM, Hewlett Packard (HP), Cisco and Dell, Cisco, for instance, receives over $90 \%$ of its product orders over the internet.
II. B2C e-commerce: or commerce between companies and consumers, involves customers gathering information; purchasing physical goods or information goods; and, for information goods, receiving products over an electronic network. It is the second largest and the earliest from of e-commerce. Its origins can be traced to online retailing (or e-tailing). Thus, the more common B2C business models are the online retailing companies such as Amazon.com, Drugstore.com, Beyon.com, Barnes and Noble and ToysRus. Other B2C examples involving information goods are E-Trade and Travelocity.

III. B2G e-commerce: is generally defined as commerce between companies and the public sector. It refers to the use of the internet for public procurement, licensing procedures, and other government-related operations. This kind of e-commerce has two features: first, the public sector assumes a pilot 'leading role in establishing e-commerce; and second, it is assumed that the public sector has the greatest need for making its procurement system more effective.

IV. C2Ce-commerce: is refers to e-commerce activities, which uses an auction style model. This model consists of person-to-person a transaction that completely excludes businesses from the equation. This type of ecommerce is characterized by the growth of electronic marketplaces and online auctions, particularly in vertical industries where firms/businesses can bid for what they want from among multiple suppliers. It perhaps has the greatest potential for developing new markets. This type of e-commerce comes in at least three forms:

- Auctions: facilitated at a portal, such as eBay, which allows online real-time bidding on items being sold in the Web.

- Peer-to-peer systems: such as the Napster model (a protocol for sharing files between users used by chat forums similar to IRC) and other file exchange and later money exchange models; and

- Classified ads at portal sites: such as Excite Classifieds and eWaanted (an interactive, online marketplace where buyers and sellers can negotiate and which features "Buyer Leads \& Want Ads").

V. M-commerce: is the buying and selling of goods and services through wireless technology i.e., handheld devices such as cellular telephones and personal digital assistants (PDAs).

\subsection{E-commerce Benefits and barriers}

The following are some Benefits and advantages of ecommerce for businesses:

- Reducing the cost of doing business. The Internet allows people from all over the world to get connected inexpensively and reliably [19].

- E-commerce serves as an "equalizer". It enables startup and small- and medium-sized enterprises to reach the global market.

- E-commerce makes "mass customization" possible. Ecommerce applications in this area include easy-to-use ordering systems that allow customers to choose and order products according to their personal and unique specifications.

- E-commerce allows "network production." This refers to the parceling out of the production process to contractors who are geographically dispersed but who 
are connected to each other via computer networks [10].

On the other hand, the main issues of concern that act as barriers are the following:

- Lack of awareness and understanding of the value of e-commerce.

- Lack of ICT knowledge and skills.

- Financial costs. The high cost of computers and Internet access is a barrier to the uptake of ecommerce.

- Infrastructure. The national network/physical infrastructure of many developing countries is characterized by relatively low teledensity, a major barrier to e-commerce.

- Security. While the appropriate policies are in place to facilitate e-commerce, lack of trust is still a barrier to using the Internet to make online transactions. Moreover, credit card usage in many developing countries is still relatively low [10].

\section{LITERATURE REVIEW}

Sait et al. introduced a report on the consequent findings, which identify factors that may significantly affect the adoption of e-commerce in the Kingdom. The study focused on Saudi Arabia's ongoing transition towards the large-scale adoption of e-commerce in the Kingdom. The factors that would most likely influence e-commerce especially within the context of its existing infrastructure, Internet awareness and social and Islamic traditions were elaborated. The work was drawn on the response of users collected through a web-based survey that lasted for two years. The survey was designed using the 'Theory of Planned Behaviour' to develop metrics for behavior and attitude towards e-commerce in the Kingdom [23].

Ho et al. argue that innovations associated with information and communication technology (ICT) have opened up new opportunities for the global economy and ushered in the age of e-commerce. The objective of this research is to explore the role of internet-based selling technology, which acts as technology infrastructure for B2C e-commerce growth at the country level. This study proposed the use of a new hybrid growth theory approach as the theoretical basis for examining exogenous and endogenous factors that influence e-commerce growth overtime. The study estimated three different models to evaluate their explanatory capabilities.

The theoretical contributions are as follows. The hybrid growth theory model explained the mechanism of ecommerce revenue growth at the national level from a new perspective. Second, the theory helped to understand the role of internet-bases selling technology adoption in e-commerce revue growth. The results showed a positive feedback relationship: increases in e-commerce revenue growth were associated with growth in secure servers, and the increase of internet-based selling technology, adoption tended to accelerate e-commerce revenue growth. Reaching this conclusion required the combination of results from different empirical estimation models.

Overall, growth theory adds to our knowledge of B2C ecommerce growth settings in the IS discipline by providing and understanding beyond some of the traditional theories of economic growth that are founded on other more general theoretical models of technology adoption and diffusion.
In terms of methodological contributions, the study demonstrated the benefits from going through a cycle of empirical estimation with multiple models, and then doing an additional assessment of what it was learned through a crossmode inference approach. The typical approach is to start with a simple representation, such as linear and separable ordinary least squares regression. FGLS mode was not able to capture the relationships that can be represented by more sophisticated models though. So the used an alternative approach, 2SLS estimation, to further examine the interactions between Internet-based selling technology adoption and e-commerce growth.

The study findings yielded insights for policy makers in three ways. First, the results show that greater internet used penetration generally accelerates e-commerce growth. Governments can make ICT policies to support internet user penetration such as preferential treatment for internet services providers and mobile telecommunication services companies.

Second, support for the development of venture capital for technology-related businesses also should stimulate technology and economic development. Government policies that specifically promote the development of venture capital should accelerate e-commerce growth.

Finally, our results suggest that capital investments, other inter-organizational, and international relationships in telecommunications may predispose a country to grow its relevant technological infrastructure, which ought to be a precursor of e-commerce revenue growth. A case in point is the formation of mobile telephony infrastructure, which serves as a basis for the future growth of mobile commerce revenue growth [15].

Mascha et al. suggest that despite rapid growth, e-commerce proponents argue that individuals are still reluctant to reveal confidential information such as credit card account numbers to unknown third parties. To reduce individual transmission and privacy risk concerns, several web sites employ encryption techniques while others include assurance seals.

This paper examined the impact of encryption on internet purchase intent (PI) in multiple vendor and product risk settings. One hundred twenty-one MBA subjects completed this online experiment. Results indicated that the presence of encryption increases the likelihood that participants make an online purchase. Further, subjects assign similar PI to encryption and assurance seal scenarios. Vendor risk moderates product risk. When the vendor was unknown, increase in the product risk (i.e. higher product price) result in decrease in PI. However, when the vendor is known, increases in product risk result increases in PI.

The results indicated that providing encryption significantly increases PI above that when no risk reliever is present and that participants assign similar PI to both encryption and assurance seal with implicit encryption scenarios. In addition, in terms of the effect of vendor and product risk on PI, the paper noted an interaction effect between vendor and product risk. Specifically, when the vendor was unknown, increases in price resulted in decreases in PI and the decrease in PI is greater for a web site with encryption than for a web site with assurance seal. However, when the vendor was known and price increased, PI was higher. Finally, we find that initial trust significantly covaries with PI. 
These findings indicate that web designers, as well as accountants advising clients, may want to focus on client attributes before deciding on a security feature to recommend. Furthermore, lesser known organizations in B2C electronic commerce may be better served devoting resources toward developing "name" awareness to attract business, as opposed to focusing on security features or price [20].

Antoniou \& Batten indicate that it has been well documented that lack of trust between commercial entities and purchasers can restrict the potential of e-commerce. This may be because the purchaser is required to provide personal information to the commercial entity, which may then be abused, or because the purchaser may be suspicious that after payment has been processed, the goods purchased will not arrive. The challenge for the researcher is to determine the e-commerce model, which maximizes the trust a purchaser has when shopping online.

This paper focused on the personal information which must be revealed by the purchaser when purchasing online and presented the first comprehensive analysis of personal information distributed in an e-commerce setting from the point of view of the purchaser and his perception of trust in an online transaction. It introduced a measure of trust based on the information distributed to the parties in the transaction and isolate the instances, which maximize trust for the purchaser relative to the personal information revealed. This leads to the establishment of a theoretical framework on which to compare e-commerce protocols and to the development of four new models, all of which, as we demonstrate, are better in concrete ways than the traditional e-commerce model based on secure e-payment protocols. Implementation of this work is likely to improve consumer trust and therefore lead to an increase in online commerce, especially in countries where privacy recognition is not strong.

This paper has established a theoretical framework on which to compare e-commerce protocols and has developed models for new protocols, all of which are better in concrete ways than the traditional e-commerce model based on secure epayment protocols.

In future work, it would be interesting to follow similar paths to measure trust of the seller and of the financial organization and of the deliverer based on their own perspectives. While the same approach can be taken, the parameters will vary for each entity and so the models may look quite different [12].

Eid aims to identify the factors that influence the extent to which Saudi consumers trust, are satisfied with, and are loyal towards B2C e-commerce. This study drew on previous research to build a conceptual framework which hypothesizes relationships between these three e-commerce constructs and their antecedents. A survey was conducted among B2C ecommerce customers in the eastern province of Saudi Arabia using a structured self-administered questionnaire. The findings of this study show that B2C e-commerce customer loyalty in Saudi Arabia is strongly influenced by customer satisfaction but weakly influenced by customer trust.

This paper attempted to examine the determinants of each of the B2C e-commerce customer satisfaction, trust and loyalty in Saudi Arabia. A theoretical research model which hypothesizes the key factors influencing the three constructs is developed and statistically validated. The identified key factors are: the user interface quality, service information quality, security risk perception, and privacy perception. Both user interface quality and information quality of e-commerce websites were found to have a significant positive impact on consumer satisfaction. While it was found that user interface quality is strongly related to customer trust, information quality was not. It was also found that both perceived security risk and perceived privacy are strongly related to customer trust, but weakly related to customer satisfaction.

Furthermore, this study investigated whether customer satisfaction and trust play a significant mediating role on Saudi consumer loyalty in B2C e-commerce services. Ecommerce customer satisfaction was found to significantly influence customer loyalty and to play the role of a partial mediator between each of the user interface quality and information quality constructs and customer loyalty. However, e-commerce customer trust was found to weakly influence customer loyalty. The user interface quality and information quality of e-commerce websites were found to be indirectly influencing Saudi e-commerce consumer loyalty. This emphasizes the importance of e-commerce service information content quality and user interface design in ecommerce application development. In addition, the level of security risk and privacy as perceived by e-commerce customers are important issues for customer trust and thus they are important to the development of $\mathrm{B} 2 \mathrm{C}$ e-commerce in Saudi Arabia. Also, both the perceived security risk and perceived privacy influence satisfaction indirectly since trust was found to play a complete mediator role between each of the perceived security risk and perceived privacy and satisfaction. The user interface quality of e-commerce websites was found to significantly influence trust. This implies that Saudi online consumers perceive those ecommerce websites as trustworthy if they provide greater level of integrity, reliability and/or credibility in their user interface. This subsequently reduces consumers' concerns of privacy and helps to build online trust toward e-commerce websites.

In this research, it was found that adoption of B2C ecommerce was higher among older, highly educated, and high-income respondents. In addition, from comparing the study findings with previous studies in other countries, it is obvious that consumer attitudes towards B2C e-commerce the developing country of Saudi Arabia are different from other international online consumers such as the Germans and Chinese with regards to trust in relation to loyalty but similar to other customers from the developed country of Canada. Thus, the level of country development is not significant with regards to online customer perceptions towards B2C ecommerce [14].

In Al-Hudhaif \& Alkubeyyer put as objectives of this study the following: 1) to find out the level of e-commerce adoption in Saudi Arabia, and 2) to identify the factors that affect the adoption of e-commerce. By this, the output of the study can help the policy maker of ICT (Information and Communication Technology) in Saudi Arabia to direct the related activities toward the most effective local factors that will enable and leverage e-commerce potential and usage on one hand, and on the other hand the study will identify the promising local opportunities for e-commerce infrastructure providers (local banks, system integrators, IT solution providers, and major telecom operators) by discovering the distinctive e-commerce adoption factors. 
By utilizing the PERM model with the two constructs PEER and POER and with its exploratory power (covering the perspective of innovation, management, organization, and environment), the study has addressed the following questions: - What is the current level of e-commerce adoption in Saudi Arabia? And - what is the group of factors or determinants that affects the decision of adoption and the level of adoption?

In general, the findings of the study can be summarized into two conclusions:

I. In Saudi Arabia, the environmental factors are more likely to affect the initial adoption of e-commerce, which is a stage of "I am there! I am online but not generating online revenue", so it is a way of the firm saying, "I hear the environment - the market forces, the supporting industry evolving, the governmental direction and regulations."

II. As firms seek a more advanced form of e-commerce adoption, then the internal organizational factors become the main determinants for such decision, and on top of these factors are the technology resources, followed by commitment, awareness, and governance. One of the external factors, then, is placing considerable importance for such decision, the market force e-readiness, which represents the required ability to adapt to the market changes and customer needs [7].

Some findings of AlGhamdi were presented from a study researching the diffusion and adoption of online retailing in Saudi Arabia. Although the country has the largest and fastest growing ICT marketplace in the Arab region, e-commerce activities have not progressed at a similar speed. In general, Saudi retailers have not responded actively to the global growth of online retailing. Accordingly, new research has been conducted to identify and explore key issues that positively and negatively influence Saudi retailers in deciding whether to adopt the online channel. While the overall research project uses mixed methods, the focus of this paper is on a quantitative analysis of responses obtained from a survey of retailers in Saudi Arabia, with the design of the questionnaire instrument being based on the findings of a qualitative analysis reported in a previous paper. The main findings of the current analysis include a list of key factors that affect retailers' decision to adopt e-commerce, and quantitative indications of the relative strengths of the various relationships.

This paper presented some findings from a study researching the diffusion and adoption of online retailing in Saudi Arabia. It identified and explored key factors influence Saudi retailers to adopt e-commerce selling to their customers. While the overall research project used mixed methods, the focus of this paper was on a quantitative analysis of responses obtained from a survey of retailers in Saudi Arabia, with the design of the questionnaire instrument being based on the findings of a qualitative analysis reported in a previous paper.

From the study findings, it can be seen clearly that the most serious inhibitors are the current habits of people in KSA do not suit online transactions, lack of clear legislations and rules of e-commerce in KSA and lack of e-commerce experience. On the other hand, the top enablers from the viewpoint of retailers are all dependent on government action, either directly or indirectly. They include provision of trustworthy and secure online payment options (ranked 1), government support and assistance for e-commerce (ranked 2), development of strong ICT Infrastructure (ranked 3) and educational programs for people and building the awareness of e-commerce in the country (ranked 4). However, responses from the $28.4 \%$ of the sample, which do have actual experience with operating an online retail business, suggest that high ratings reflect some unrealistic expectations about the true efficacy of the enablers.

The most relevant practical implications of this paper are probably those which can be drawn from the responses of Saudi businesses which already have experience making online sales to Saudi customers. According to them, the most serious inhibitors are unfavorable Saudi consumer habits, lack of government regulations, and lack of online payment options. Retailers with previous online sale experience also provide clear and practical indications as to the top enabling factors. These are developing online payment options, enhancing ICT infrastructure and government regulations and support. Therefore, the government and the industry should pay attentions to these factors to facilitate e-retail growth in the country. The critical question, then, becomes whether there are valid justifications for the government to take such an interventionist role in normal commerce, as opposed to the cases of e-government and e-learning which involve public services or "social" goods. Such a question must be left to future research [5].

AlGhamdi et al. suggest that the issues that influence online retailing in Saudi Arabia were explored. Retailers in Saudi Arabia have been reserved in their adoption of electronically delivered aspects of their business. Despite the fact that Saudi Arabia has the largest and fastest growth of ICT marketplaces in the Arab region, e-commerce activities are not progressing at the same speed. Only very few Saudi companies, mostly medium and large companies from the manufacturing sector, are involved in e-commerce implementation.

Based on qualitative data collected by conducting interviews with 16 retailers and 16 potential customers in Saudi Arabia, several factors influencing online retailing diffusion in Saudi Arabia are identified. However, government support comes the highest and most influencing factor for online retailing growth as identified by both parties; retailers and potential customers in Saudi Arabia.

This paper has investigated the issues that positively and negatively influence online retailing growth in Saudi Arabia. It came up with several issues inhibiting and driving towards online retailing in Saudi Arabia. However the government support seems to be the missing key for online retailing support and growth in Saudi Arabia. Therefore, policy makers and developers should pay attentions to these factors and the Saudi government should take serious role to facilitate online retailing growth in KSA. However, this study is still in progress in due course to be able to develop a model in order to contribute to e-commerce development in Saudi Arabia [6].

Al-Otaibi \& Al-Zahrani's study is one of the first scientific studies of Saudi commercial web sites. They analyzed the practices and the characteristics of web sites. Their study measured the tendency of Saudi organizations towards ecommerce. The investigation considered the marketing, human interaction, knowledge support and e-commerce dimensions within those sites. Today's Saudi e-commerce practices are generally immature, where most of the previous dimensions are either missing or very weak. This paper offers an insight into the status of e-commerce in Saudi Arabia. 
Despite the fact that our survey is not exhaustive, we claim that the results reached in this paper reflected -to a large extent- the current situation, and could be used by responsible authorities to find means to encourage those practices and overcome weaknesses and barriers.

Saudi web sites are not e-commerce-oriented and have very weak marketing facilities, human interaction methods and knowledge support tools. They are mainly small in size, static, poor in knowledge and advertisement-oriented. In the marketing dimension, they are not targeting the right audience, they are limited in focusing on customer needs, and they are also not customizable. In the human interaction dimension, Saudi web sites are to- some extent- not easy to use and not safe. Most of them are attractive and scalable and $63 \%$ of them are highly available.

Knowledge support was generally poor in Saudi web sites. Although most sites had reasonable content, this content was not designed to serve different classes of web site visitors. Furthermore, sites are not equipped with tools for interaction and sharing of knowledge. These are two essential components of a successful web site.

In the e-commerce dimension, most of the Saudi web sites are very weak in buying and selling facilities and do not apply transaction processing, trust, e-Payment, and rewards and loyalty programs.

The current Saudi e-commerce practices are immature since each of the previous dimensions is either missing or very weak. Extreme care must be given to the design of Saudi web sites. They must be utilized for actual business and should be equipped with facilities for true e-commerce. Further investigation is required to give a clear evaluation of ecommerce in Saudi Arabia. This includes evaluating infrastructure impact, ISP quality of service, and organizational issues of e-commerce within organizations. Some of these are tackled in [9].

\section{TRUST FACTORS OF E-COMMERCE}

Customer trust can be defined as a set of beliefs held by an online consumer concerning certain characteristics of the esupplier, as well as the possible behavior of the e-supplier in the future. Trust encourages online purchasing and affects customer attitudes towards purchasing from e-retailers ${ }^{26}$. In this section we introduce the trust factors that affect the increase and/or decrease the e-commerce transactions in Saudi Arabia. We have categorized the e-commerce trust factors that consistent with the traditions of Saudi Arabia and maximize the purchaser trust when on-line shopping, into five factors that includes:

\subsection{Human Interaction Factors:}

1.1 Easiness: includes assisting users while browsing the site, navigation simplicity, clarity of site organization, automated help, and support.

1.2 Attractiveness: includes visualization approach, presented material, and entertainment facilities offered.

1.3 Obviousness: includes providing users with well designed sites and as close as possible to the real world.

1.4 Encouragement: includes understanding the user's tasks, and meeting user expectations.
1.5 Availability: includes download speed and browsing speed.

1.6 Competitively: includes providing competitive prices, and high quality goods.

1.7 Generation gap: include continuing update and improvement. Language barrier.

\subsection{E-Commerce Factors:}

1.8 Transaction processing: include facilities of transaction processing needed when the shopper proceeds to the virtual checkout counter. Software needs to calculate price, volume discounts, and shipping costs and then execute the operation on the database and generate a receipt to the customer.

1.9 Buying and selling facilities: include shopping items display, item description details level, and complementary product offers.

1.10 Rewards and loyalty: many sites present rewards (e.g., scores, credit money, prizes, competitions, etc...) to their consumers to gain user loyalty and ensure that the consumer will visit the site again (i.e., customer retention).

1.11 Scalability: includes the evaluation of growth potential of the site (i.e., evaluates whether the site is deigned with future expansion or shrinking in mind).

1.12 E-commerce infrastructure: include providing strong infrastructure and security.

1.13 Financial services: include providing trusted and secure financial services.

\subsection{Marketing Factors:}

1.14 Targeting the right audience: through advertisement and products suitability.

1.15 Providing service' centers: includes determining and reaching potential customers, identifying their needs, and promoting products to meet those needs.

1.16 Customizability: includes collecting information about individual customers and providing services accordingly.

\subsection{Knowledge Factors:}

1.17 Richness of the site.

1.18 Covering for different types of customers, and meet all needs.

1.19 Support for knowledge publishing.

\subsection{Security Factors:}

1.20 Trust: includes checking of (site Legality, stability of company information, identification and certification of the products).

1.21 E-Payment support: includes the use of technologies in electronic payment (e.g. credit cards, charge cards, e-Cash, e-Wallet, and smart cards).

1.22 Safety: includes safety from errors that covers eliminating end user mistakes and effectiveness of aiding tools (e.g. lists and choices).

1.23 Privacy: includes perceiving consumers regarding the handling of their private data: As the perception of privacy risk decreases, customer trust increases.

1.24 Measures policies, laws and incentives: includes focusing on promoting trust and confidence among e-commerce participants 


\section{RESEARCH METHODOLOGY}

The main objective of this research paper is to identify and analyze the main factors that influence Saudi consumers' trust towards the $\mathrm{B} 2 \mathrm{C}$ e-commerce. The quantitative analysis of responses obtained from a survey and questionnaire of selected customers and businesses in Saudi Arabia. The researcher used business to business (B2B) model as one of the e. commerce models. The researcher approved the validity of the questionnaire as shown the following tables:

Table 1: The correlation coefficients (first axis and the total degree of the same axis)

\begin{tabular}{|c|c|}
\hline $\begin{array}{c}\text { The phrases of the first } \\
\text { axis }\end{array}$ & $\begin{array}{c}\text { The correlation coefficient with } \\
\text { the total degree of the axis }\end{array}$ \\
\hline 1 & $* * .652$ \\
\hline 2 & $* * .665$ \\
\hline 3 & $* * .606$ \\
\hline 4 & $* * .646$ \\
\hline 5 & $* * .616$ \\
\hline 6 & $* * .569$ \\
\hline 7 & $* * .610$ \\
\hline 8 & $* * .638$ \\
\hline 9 & $* * .722$ \\
\hline 10 & $* * .697$ \\
\hline 11 & $* * .658$ \\
\hline 12 & $* * .687$ \\
\hline 13 & $* * .733$ \\
\hline 14 & $* * .628$ \\
\hline
\end{tabular}

** The correlation is significant at the level of 0.01

Table 2: The correlation coefficients (second axis and the total degree of the same axis)

\begin{tabular}{|c|c|}
\hline $\begin{array}{c}\text { The phrases of the second } \\
\text { axis }\end{array}$ & $\begin{array}{c}\text { The correlation coefficient with } \\
\text { the total degree of the axis }\end{array}$ \\
\hline 1 & $* * .659$ \\
\hline 2 & $* * .701$ \\
\hline 3 & $* * .616$ \\
\hline 4 & $* * .691$ \\
\hline 5 & $* * .593$ \\
\hline 6 & $* * .559$ \\
\hline 7 & $* * .725$ \\
\hline 8 & $* * .663$ \\
\hline
\end{tabular}

Table 3: The correlation coefficients between

(Third axis and the total degree of the same axis)

\begin{tabular}{|c|c|}
\hline $\begin{array}{c}\text { The phrases of the third } \\
\text { axis }\end{array}$ & $\begin{array}{c}\text { The correlation coefficient with the } \\
\text { total degree of the axis }\end{array}$ \\
\hline 1 & $* * .568$ \\
\hline 2 & $* * .842$ \\
\hline 3 & $* * .863$ \\
\hline 4 & $* * .844$ \\
\hline 5 & $* * .666$ \\
\hline
\end{tabular}

Table 4: The correlation coefficients (fourth axis and the total degree of the same axis)

\begin{tabular}{|c|c|}
\hline $\begin{array}{c}\text { The phrases of the } \\
\text { fourth axis }\end{array}$ & $\begin{array}{c}\text { The correlation coefficient with the total } \\
\text { degree of the axis }\end{array}$ \\
\hline 1 & $* * .745$ \\
\hline 2 & $* * .822$ \\
\hline 3 & $* * .797$ \\
\hline
\end{tabular}

Table 5: The correlation coefficients (fifth axis and the total degree of the same axis)

\begin{tabular}{|c|c|}
\hline $\begin{array}{c}\text { The phrases of the fifth } \\
\text { axis }\end{array}$ & $\begin{array}{c}\text { The correlation coefficient with the } \\
\text { total degree of the axis }\end{array}$ \\
\hline 1 & $* * .804$ \\
\hline 2 & $* * .722$ \\
\hline 3 & $* * .822$ \\
\hline 4 & $* * .741$ \\
\hline 5 & $* * .787$ \\
\hline 6 & $* * .798$ \\
\hline
\end{tabular}

Table 6: The correlation coefficients

(Each axis of the questionnaire and the total degree of the questionnaire)

\begin{tabular}{|c|c|}
\hline $\begin{array}{c}\text { The axes of the } \\
\text { questionnaire }\end{array}$ & $\begin{array}{c}\text { The correlation coefficients with the total } \\
\text { degree }\end{array}$ \\
\hline The first axis & $* * .864$ \\
\hline The second axis & $* * .775$ \\
\hline The third axis & $* * .671$ \\
\hline The fourth axis & $* * .708$ \\
\hline The fifth axis & $* * .680$ \\
\hline
\end{tabular}

It is clear that from Table 6 , the values of correlation coefficients of each axis of the questionnaire are positive and statistically significant at the level of 0.01 or less, which proves that the questionnaire's phrases have a good degree of validity which can be relied upon to conduct the study.

Table 7: The reliability of the questionnaire using Cranach's Coefficient Alpha

\begin{tabular}{|c|c|}
\hline Phrases & Cranach's Coefficient Alpha \\
\hline The first axis & .8372 \\
\hline The second axis & .8404 \\
\hline The third axis & .8611 \\
\hline The fourth axis & .8349 \\
\hline The fifth axis & .8557 \\
\hline $\begin{array}{c}\text { The total reliability of the } \\
\text { questionnaire }\end{array}$ & .8612 \\
\hline
\end{tabular}

Table 7, shows that the questionnaire has a high reliability coefficient as the reliability ratio for all axes reached (.8612), this ratio is high and appropriate and also reassures the researcher to use this instrument as a tool for gathering information, answer the questions of the study and trust the results of its application. The authors have used some statistical methods appropriate to the nature and type of the available data used in the Statistical Package for Social Science (SPSS) which include: Simple frequency tables, arithmetic means, percentages and Pearson's correlation coefficient in order to obtain the required data for this study.

\subsection{Results, discussions and interpretations}

The statistical description of the study sample according to the characteristics and traits of the study sample are used for data analysis, these characteristics are related to (age, gender, region, level of education, job, and monthly income). Table 8 , shows the results of the study sample according to the age variable: 
Table 8: The distribution of the study sample according to the age variable

\begin{tabular}{|c|c|c|}
\hline Age & Frequency & Percentage \\
\hline Less than 20 years old & 7 & $3.1 \%$ \\
\hline From 20 to 30 years old & 129 & $56.8 \%$ \\
\hline From 31 to 40 years old & 72 & $31.7 \%$ \\
\hline More than 40 years old & 19 & $8.4 \%$ \\
\hline Total & 227 & $100 \%$ \\
\hline $\begin{array}{c}\text { More } \\
\text { than } 40 \\
\text { years old } \\
8 \% \\
\text { From } 31 \\
\text { to } 40 \\
\text { years old } \\
32 \%\end{array}$ & & $\begin{array}{l}\text { sthan } \\
\text { years } \\
\text { old } \\
3 \% \\
\\
\text { m } 20 \\
30 \\
\text { ars old } \\
7 \%\end{array}$ \\
\hline
\end{tabular}

It is clear from table 8 , that the study sample whose ages ranged between (20-30 years old) represent $(56.8 \%)$ of the total sample, the study sample whose ages ranged between (31-40 years old) represent (31.7), the study sample whose ages are more than (40 years old) represent $(8.4 \%)$ while the study sample whose ages are less than (20 years old) represent $(3.1 \%)$. On the other hand Table 9, shows that $(70.0 \%)$ of the study sample are males while (30.0\%) are females.

Table 9: The distribution of the study sample according to the gender variable

\begin{tabular}{|l|c|c|}
\hline Gender & Frequency & Percentage \\
\hline Male & 159 & $70.0 \%$ \\
\hline Female & 68 & $30.0 \%$ \\
\hline Total & 227 & $100 \%$ \\
\hline
\end{tabular}

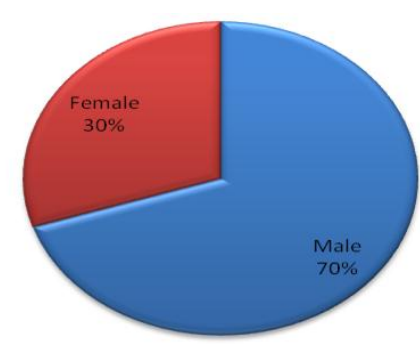

Table 10, shows that $(70.0 \%)$ of the study sample are from the central region, $(13.2 \%)$ are from the southern region, $(7.5 \%)$ are from the western region, $(5.3 \%)$ are from the eastern region while $(4.0 \%)$ from the northern region.

Table 10: The distribution of the study sample according to the region variable

\begin{tabular}{|l|c|c|}
\hline Region & Frequency & Percentage \\
\hline Northern region & 9 & $4.0 \%$ \\
\hline Southern region & 30 & $13.2 \%$ \\
\hline central region & 159 & $70.0 \%$ \\
\hline Eastern region & 12 & $5.3 \%$ \\
\hline Western region & 17 & $7.5 \%$ \\
\hline Total & 227 & $100 \%$ \\
\hline
\end{tabular}

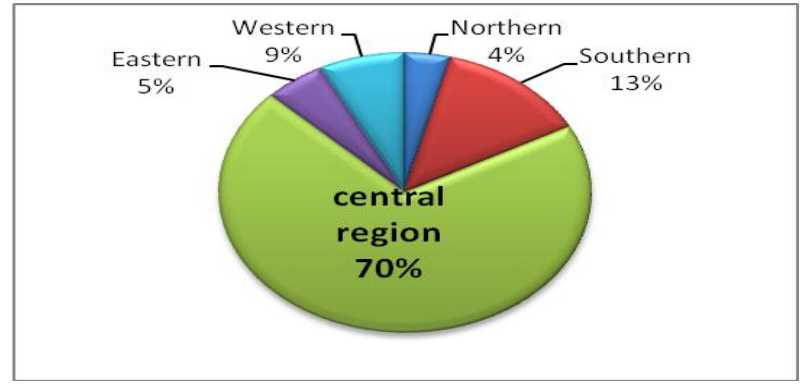

Table 11, shows that $(72.2 \%)$ of the study sample have university degrees, $(17.2 \%)$ have general degrees, $(9.7 \%)$ have higher degrees, while $(0.9 \%)$ are uneducated.

Table 11: The distribution of the study sample according to the level of education variable

\begin{tabular}{|l|c|c|}
\hline Level of education & Frequency & Percentage \\
\hline Uneducated & 2 & $.9 \%$ \\
\hline General education & 39 & $17.2 \%$ \\
\hline $\begin{array}{l}\text { University } \\
\text { education }\end{array}$ & 164 & $72.2 \%$ \\
\hline Higher education & 22 & $9.7 \%$ \\
\hline Total & 227 & $100 \%$ \\
\hline
\end{tabular}

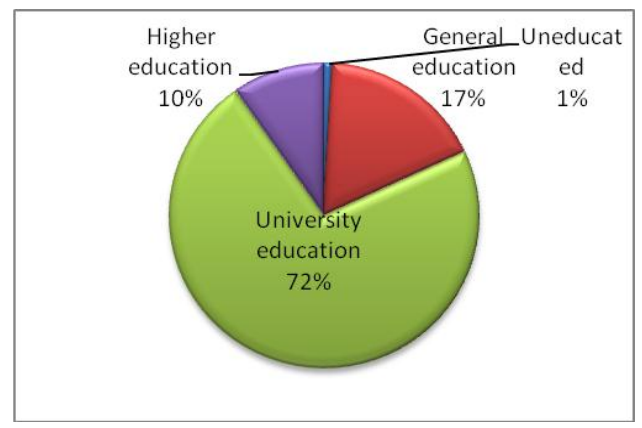

Table 12, shows that $(41.0 \%)$ of the study sample are employees in the public sector, $(34.8 \%)$ are employees in the private sector, while $(24.2 \%)$ are employees worked in other jobs.

Table 12: The distribution of the study sample according to job variable

\begin{tabular}{|l|c|c|}
\hline Job & Frequency & Percentage \\
\hline Public sector & 93 & $41.0 \%$ \\
\hline Private sector & 79 & $34.8 \%$ \\
\hline Others & 55 & $24.2 \%$ \\
\hline \multicolumn{1}{|c|}{ Total } & 227 & $100 \%$ \\
\hline
\end{tabular}

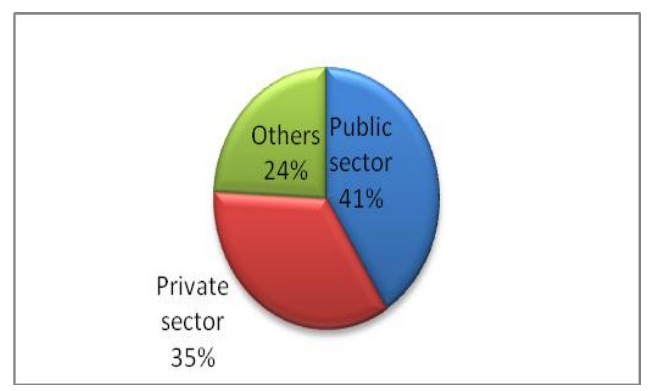

Table 13 , shows that $(58.1 \%)$ of the study sample have monthly income ranged between $(5000-20000$ SR), (33.0\%) 
have monthly income less than (5000 SR), (7.9\%) have monthly income ranged between (20001 - $40000 \mathrm{SR}),(.9 \%)$ have monthly income more than (40000 SR). Data given here prove that there are an increase in the percentage of those who have monthly income ranged between $(5000-20000 \mathrm{SR})$ in comparison with those who have monthly income more than (40000 SR) among the study sample.

Table 13: The distribution of the study sample according to the monthly income variable

\begin{tabular}{|l|c|c|}
\hline Monthly income & Frequency & Percentage \\
\hline Less than 5000 SR & 75 & $33.0 \%$ \\
\hline $5000-20000 \mathrm{SR}$ & 132 & $58.1 \%$ \\
\hline $20001-40000 \mathrm{SR}$ & 18 & $7.9 \%$ \\
\hline More than 40000 SR & 2 & $.9 \%$ \\
\hline Total & 227 & $100 \%$ \\
\hline
\end{tabular}

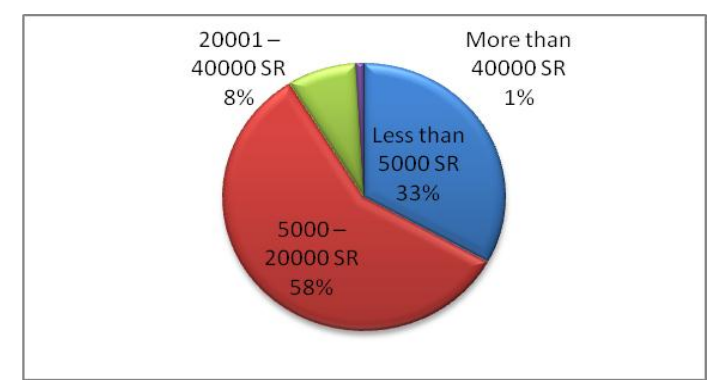

Table 14: shows that the percentages of the responses of the study sample towards the phrases of the first axis related to the human interaction which encourage the online purchasing and affect the attitudes of the customers towards purchasing from electronic retail marketers, ranged between $(4.05 \%$ $4.49 \%$ ) for all the responses of the study sample this means that the phrases of this axis are achievable with a high degree.

Table 14: Presentation and analysis the results related to Questions survey

\begin{tabular}{|c|c|c|c|c|c|c|c|c|c|c|c|c|c|}
\hline \multirow{2}{*}{\multicolumn{2}{|c|}{$\%$}} & & & & Phrases & \begin{tabular}{|l} 
Strondy \\
agree
\end{tabular} & aggee & neutral & dissagee & $\begin{array}{l}\text { strondy } \\
\text { disagee }\end{array}$ & \multirow[t]{2}{*}{ means } & \multirow[t]{2}{*}{$\begin{array}{l}\text { Standard } \\
\text { deviations }\end{array}$} & \multirow[t]{2}{*}{ rank } \\
\hline & & freq & $\%$ & freq $1 \%$ & & freq & $\%$ & freq & $\%$ & freq & & & \\
\hline Phl & 36.6 & 83 & 50.7 & \begin{tabular}{|l|l|}
115 & 1 \\
\end{tabular} & 10.6 & 24 & 1.3 & 3 & 9 & 2 & 4.21 & .75 & seventh \\
\hline $\mathrm{Ph} 2$ & 35.2 & 80 & 54.2 & 1238 & 8.8 & 20 & 1.8 & 4 & 0 & 0 & 4.23 & .68 & sixth \\
\hline $\mathrm{Ph} 3$ & 29.5 & \begin{tabular}{|l|l|}
67 \\
\end{tabular} & 55.9 & 1271 & 12.3 & 28 & 2.2 & 5 & 1 & 0 & 4.13 & .70 & Tenth \\
\hline $\mathrm{Ph} 4$ & 45.8 & 104 & 41.9 & \begin{tabular}{l|l}
95 & 1 \\
\end{tabular} & 11.5 & 26 & .4 & 1 & .4 & 1 & 4.32 & .73 & Fourth \\
\hline $\mathrm{Ph} 5$ & 36.1 & 82 & 45.8 & \begin{tabular}{|l|l|}
104 & 1 \\
\end{tabular} & 15.9 & 36 & 2.2 & 5 & & 0 & 4.16 & .77 & ninth \\
\hline Ph6 & 46.7 & 106 & 43.6 & \begin{tabular}{|l|l}
99 & 7.
\end{tabular} & 7.9 & 18 & 9 & 2 & .9 & 2 & 4.34 & .74 & Eleventh \\
\hline $\mathrm{Ph} 7$ & 46.7 & 106 & 43.6 & \begin{tabular}{|l|l}
99 & 7. \\
\end{tabular} & 7.9 & 18 & 9 & 2 & .9 & 2 & 4.34 & .74 & third \\
\hline $\mathrm{Ph} 8$ & 34.8 & 79 & 44.1 & \begin{tabular}{|l|l|l}
100 & 18 \\
\end{tabular} & 18.9 & 43 & 1.8 & 4 & .4 & 1 & 4.11 & .80 & twelifth \\
\hline $\mathrm{Ph} 9$ & \begin{tabular}{|l|}
37.4 \\
\end{tabular} & 85 & 40.5 & \begin{tabular}{|l|l|}
92 & 1 \\
\end{tabular} & 17.2 & 39 & 3.5 & 8 & 103 & 3 & 4.09 & 0.90 & Thirteenth \\
\hline Ph10 & 37.4 & 85 & 37.0 & \begin{tabular}{|l|l|}
84 & 1 \\
\end{tabular} & 19.8 & 45 & 4.4 & 10 & 1.3 & 3 & 4.05 & .93 & fourteenth \\
\hline Ph11 & 52.4 & 119 & 32.2 & \begin{tabular}{|l|l}
73 & 1 \\
\end{tabular} & 12.3 & 28 & 1.3 & 3 & 1.8 & 4 & 4.32 & .87 & fifth \\
\hline Ph12 & 61.2 & 139 & 29.1 & \begin{tabular}{|l|l}
66 & 7. \\
\end{tabular} & 7.9 & 18 & 1.3 & 3 & .4 & 1 & 4.49 & .74 & first \\
\hline $\mathrm{Ph} 13$ & 40.5 & 92 & 41.4 & \begin{tabular}{|l|l|}
94 & 1 \\
\end{tabular} & 15.9 & 36 & 2.2 & 5 & 0 & 0 & 4.20 & .78 & eighth \\
\hline Ph14 & 53.3 & 121 & 30.0 & \begin{tabular}{|l|l|}
68 & 1 \\
\end{tabular} & 15.4 & 35 & 1.3 & & 0 & 0 & 4.35 & .79 & second \\
\hline
\end{tabular}

\subsection{Analysis Summary and Recommendations}

1) The most important factors related to human interaction which encourage electronic purchasing and affect the client's attitude towards purchasing from electronic retail marketers are:
- The high quality of products positively affects my decision to buy.

- Linguistic consistency (knowing the language) helps me to know the benefits of the product.

2) The most important factors of the concept of e-commerce which encourage electronic purchasing and affect the client's attitude towards purchasing from electronic retail marketers are:

- Providing reliable and safe financial services encourage me to sign the deal.

- Providing strong and safe infrastructure is the key component to construct trust.

3) The most important factors of marketing concept which encourage electronic purchasing and affect the client's attitude towards purchasing from electronic retail marketers are:

- The process of collecting information about clients and providing services according to it is considered an important key in shopping world.

- The advertisement and suitable products attract target clients.

4) The most important factors of knowledge (information) which encourage electronic purchasing and affect the client's attitude towards purchasing from electronic retail marketers are:

- Covering different clients' categories and meeting their needs are of the most important confidence factors.

- The cognitive richness (informational) of the site is rated as one of the most important and required confidence factors during shopping process.

5) The most important factors of security (information security) which encourage electronic purchasing and affect the client's attitude towards purchasing from electronic retail marketers are:

- Verifying the legitimacy of the site and the accuracy of the company's data, in addition to being sure of the identity and the product's warranty certificate are considered of the most important confidence factors during online shopping.

- The client's confidence in the site increases the security factor during making the decision of buying.

In the light of the current study results, the researcher suggests the some recommendations which include:

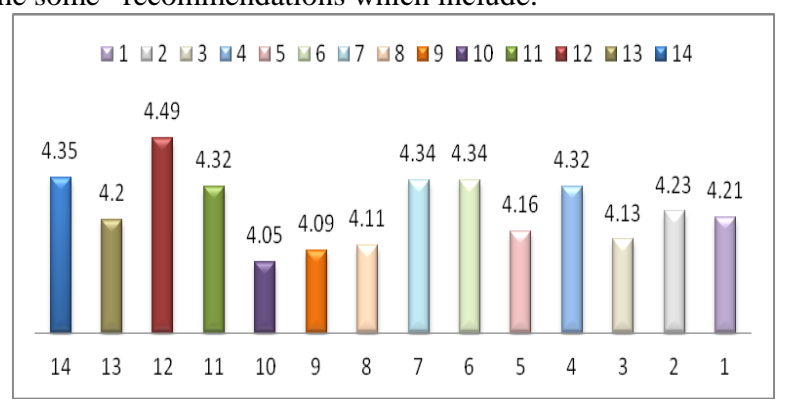

1) Establishing suitable strategies to develop the communication sector in the Kingdom of Saudi Arabia.

2) Providing sites with technical characteristics that add attractiveness to the site and motivate the clients towards these sites.

3) The possibility of making video and audio calls immediately without any limits or restrictions will lead to increase the volume of e-commerce.

4) Establishing methods of legal protection to solve payments via internet and credit cards problems. 
5) Establish the appropriate law to control e-commerce operations.

6) Establishing research and development centers to provide counseling and help people in the field of e-commerce.

\section{CONCLUSION}

In this study we have identified and analyzed the main factors that influence the extent to which Saudi consumers trust towards the B2C e-commerce. The study also presented and identified five trust factors that consistent with the traditions of Saudi Arabia and maximizes the purchaser trust when shopping through the internet. The paper concluded with quantitative analysis of responses obtained from a survey and questionnaire of selected customers and businesses in Saudi Arabia. The main results of this analysis included a relationship of key factors that affect the trust of Saudi consumers in the e-commerce, and the indicators of strengths and weaknesses that affect these factors.

\section{ACKNOWLEDGMENT}

The authors acknowledge the full support received from Arab East Colleges for Graduate Studies, especially they very thankful to Professor Dr. Abd Allah Alfaisal, Dean of the Colleges, for his encouragement and support.

\section{REFERENCES}

[1] Agamdi, A e-Commerce Implementation Challenges and Success Factors in the Kingdom of Saudi Arabia, in 19th National Computer Conference: the digital economy and ICT industry. 2008: Riyadh.

[2] Aladwani, A.M. Key Internet characteristics and $e$ commerce issues in Arab countries. Information and Management, 16(1), 9-20, 2003.

[3] Albadr, B.H. E-commerce. Science and Technology, (65), 14-19, 2003

[4] Alfuraih, S. E-commerce and E-commerce Fraud in Saudi Arabia: A Case Study. in 2nd International Conference on Information Security and Assurance. Busan, Korea: Institute of Electrical and Electronics Engineers (IEEE), 2008.

[5] AlGhamdi, R. ; Drew, S.; \& Alfaraj, O. Issues influencing Saudi customers' decisions to purchase from online retailers in the KSA : a qualitative analysis. European Journal of Scientific Research, (in press), 2008

[6] AlGhamdi, R.; Drew, S. and Alkhalaf, S. Government Initiatives: The Missing Key for E-commerce Growth in KSA, World Academy of Science, Engineering and Technology 77 2011, pp. 772-775.

[7] Al-Hudhaif, Sulaiman \& Alkubeyyer, Abdullah. ECommerce Adoption Factors in Saudi Arabia, International Journal of Business and Management Vol. 6, No. 9; September 2011, pp. 122-133.

[8] Al-Otaibi M.B.; \& Al-Zahrani, R.M. E-commerce Adoption in Saudi Arabia: An Evaluation of Commercial Organizations' Web Sites. King Saud University: Riyadh, 2003.

[9] Al-Otaibi, Mutlaq \& Al-Zahrani, Rasheed M. ECommerce Adoption in Saudi Arabia: An Evaluation of Commercial Organizations' Web Sites, Information systems department, College of computer and information sciences, King Saudi University.

[10] Andam, Zorayda Ruth (2003). E-commerce and ebusiness, e-ASEAN Task Force, UNDP-APDIP.
[11] Antoniou, Giannakis \& Batten, Lynn. E-commerce: protecting purchaser privacy to enforce trust. Electron Commer Res (2011) 11:421-456.

[12] Chang, E., Dillon, T., \& Hssain, F. (20060> trust and reputation for service-oriented envrionments. New York: Wiley.

[13] Eid, Mustafa. Determinants of E-Commerce Customer Satisfaction, Trust, and Loyalty in Saudi Arabia, Journal of Electronic Commerce Research, VOL 12, NO 1, 2011, pp. 78-93

[14] Ho, Shu-Chun; Kauffman, Robert J.; Liang, Thing-Peng (2011). Internet-based selling technology and ecommerce growth: a hybrid growth theory approach with cross-model inference. Electron Commer Res (2011) 12: 409-429.

[15] Hu, X., Wu, G., Wu, Y., \& Zhang, H. (2010). The effects of web assurance seals on consumers' initial trust in an online vendor: a functional perspective. Decision support systems, 48(2), 407-418).

[16] Kim, D. \& Benbasat, I. (2010). Designs for effective implementation of trust assurances in internet stores. Communications of the ACM, 53(2), 121-126.

[17] Kovar, S. E., Burke, K. G., \& Kovar, B. R. (2000) Consumer responses to the CPA WebTrust assurance. Journal of information systems, 14(1), 3-17.

[18] Lallana, Quimbo, Andam, 4. Cf. Ravi Kalakota and Andrew B. Whinston, Electronic Commerce: A Manager's Guide (USA: Addison Wesley Longman, Inc., 1997), 19-20.

[19] Mascha, Maureen Francis; Miller, Cathleen L. \& Janvrin, Dian J.. The effect of encryption on Internet purchase intent in multiple vendor and product risk setting. Electron Commer Res (2011) 11: 401-419.

[20] Mustafa I. Eid, "Determinants of E-Commerce Customer Satisfaction, Trust, and Loyalty in Saudi Arabia". Journal of Electronic Commerce Research, VOL 12, NO 1, 2011.

[21] Pennington, R., Wilcox, H. D., \& Grover, V. (2003). The role of system trust in business-to-consumer transactions. Journal of management information systems, 20(3), 197 226).

[22] Qin, Zheng; Shungond, Li; Yi, Han; Jinchun, Dong; Lixiang, Yan; Jun, Qin (2009). Introduction to Commerce, New York: Springer Berlin Heidelberg).

[23] Sait, Sadiq; Al-Tawil, Khalid \& Hussain, Syed Ali. ECommerce in Saudi Arabia: Adoption and Perspectives, AJIS, Vol. 12, no. 1, September 2004, pp. 54-74

[24] Saudi Ministry of Commerce, E-commerce in the kingdom: Breakthrough for the future. Riyadh: Saudi Ministry of Commerce, 2001.

[25] Spikermann, S., Grossklags, J., \& Berendt, B. (2001). Eprivacy in $2^{\text {nd }}$ generation e-commerce: privacy preferences versus actual behavior (pp. 38-47). New York: ACM.

[26] Teo, T. S. H.; \& Liu, J. (2007). Consumer trust in ecommerce in the united states, Singapore and china omega, 35, 22-38.

[27] U.S. Department of Commerce, Doing Business In Saudi Arabia: A Country Commercial Guide for U.S. Companies. U.S. \& Foreign Commercial Service and U.S. Department of State, 2008 